\title{
EL BASILISCO: MITO, FOLCLORE Y DIALECTO ${ }^{1}$
}

JosÉ LUIS MOURE

Universidad de Buenos Aires SECRIT (CONICET)

In memoriam Alberto M. Salas

Un monstruo, señaló Jorge Luis Borges, no es otra cosa que una combinación de elementos de seres reales, aunque - previno- las posibilidades del arte combinatorio lindan con lo infinito $^{2}$. Frente a las piezas que compusieron la riquísima zoología imaginaria de los antiguos, agregado de seres nacidos de los miedos y de los sueños, es nuestro propósito fijar la atención en el basilisco, criatura horrenda y de empecinada resistencia al olvido.

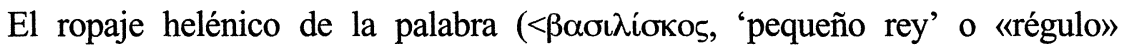
- versión esta menos favorecida por nuestra tradición léxica-) puede disimular el hecho de que fue la literatura latina la que nos guardó la primera información verbal sobre este cuasi-reptil mortífero. Plinio el Viejo lo hace originario de la Cirenaica africana y nos brinda las necesarias precisiones: longitud no mayor de doce dedos y en la cabeza una mancha blanca en forma de diadema (candida in capite macula ut quodam diademate), a diferencia de las otras serpientes no se desplaza replegándose sobre sí mismo sino irguiéndose sobre su parte media (celsus et erectus in medio incedens), su silbido espanta al resto de los reptiles (sibilo omnes fugat serpentes), y a su simple contacto, o apenas alcanzados por su aliento, mueren los arbustos, arden las hierbas y se quiebran las piedras (necat frutices, non contactos modo verum et afflatos: exurit herbas,

\footnotetext{
${ }^{1}$ En San Fernando del Valle de Catamarca, ciudad capital de la provincia argentina de Catamarca, expusimos una forma reducida del presente trabajo para el XIV Simposio Nacional de Estudios Clásicos (Facultad de Humanidades de la Universidad Nacional de Catamarca, 17-20 de septiembre de 1996). Conste nuestro agradecimiento a Ianir Milevski, Lilia Ferrario de Orduna y María Leguizamón, quienes respondieron a nuestras consultas con generosa entrega de su tiempo e información.

${ }^{2}$ Cf. Jorge Luis Borges y Margarita Guerrero, Manual de zoología fantástica, México, FCE, 1957, prólogo, pág. 8 .
} 
rumpit saxa). La potencia mortífera del basilisco es tal que su ponzoña puede ascender por la lanza con la que un jinete intente herirlo y acabar con la vida del caballero y aun del caballo. Las cavernas donde se esconde pueden reconocerse por el suelo quemado que las rodea. Mas como a la naturaleza le placen las contrapartes - nos consuela Plinio- el monstruo sucumbe ante la fetidez de la comadreja, la que en el mismo acto muere con él ${ }^{3}$.

La cumplida referencia que acabamos de citar es seguramente tardía. Serpientes con cresta ilustraban vasos griegos y etruscos, en representaciones acaso vinculadas con las najas y ofidios cornados del norte de África y del poniente de $\mathrm{Asia}^{4}$. Y en la misma Roma el vocablo hubo de tener más temprana difusión si nos atenemos al cognomen de Basiliscus que sobrellevaba Pompeyo, según una involuntaria información de Cicerón ${ }^{5}$.

Tres severos hexámetros de la Farsalia, poco anteriores a la descripción de Plinio y seguramente conocidos por éste, habían compuesto una efectiva semblanza del espanto. Lucano, refiriendo cómo de la sangre de Medusa, decapitada por Perseo, nacieron todos los reptiles de Libia, y tras describir las funestas propiedades de cada uno de los integrantes de este nutrido serpentario (el áspid, la hemorrois, el quersidro, los quelidros, el cencris, el hamodites, el cerastes, el escítale, la dípsada, el nátride, la anfisbena, los yáculos, el parias, el préster, el amódite y el sepe), concentró en unos expresivos metros los rasgos del basilisco:

sibilaque effundens cunctas terrentia pestes, ante uenena nocens, late sibi summouet omne uolgus et in uacua regnat basiliscus harena. [Libro IX, vv. 724-726.]

['Lanzando silbidos que aterrorizan al resto de las sierpes, dañando antes de envenenar, ahuyentando vastamente a toda criatura reina el basilisco en la arena vacía'] $]^{6}$.

${ }^{3}$ C. Plinius Secundus, Histoire naturelle, Paris, Didot, 1865, vol. I, 1. VIII, pág. 331, §33. El pernicioso efecto del basilisco sobre las plantas parece haber permanecido en la memoria popular siciliana, cuyo dialecto conserva el verbo abasiliskari con el sentido de 'marchitarse', 'secarse', 'arruinarse'; cf. Ernst Gamillscheg, Etymologisches Wörterbuch der französischen Sprache, Heidelberg, Carl Winters Universitätsbuchhandlung, 1928, s.v. basilic.

${ }^{4}$ Cf. The Bible Dictionary, London, Cassell, Petter, Galpin, 1883, s.v. cockatrice, pág. 283. Cf. Maria Leach (ed.), Funk \& Wagnalls Standard Dictionary of Folklore Mithology and Legend, Nueva York, Funk \& Wagnall, 1949, pág. 117.

5 «Nam ipsi Tullio patebat domus locupletissima et amplissima Cn. Pompei Basilisci», $M$. Tulli Ciceronis in C. Verrem Actionis Secundae Liber IV de Signis, en Cicéron, Discours, París, Les Belles Lettres, 1944, tomo V, pág. 20.

${ }^{6}$ A. Bourgery y Max Ponchont (eds.), Lucain. La Guerre Civile (La Pharsale). Texte établi et traduit par [...]. París, Les Belles-Lettres, 1948, tomo II, pág. 163. La traducción es nuestra. Estos mismos pasajes de Plinio y Lucano son comentados por Gerardo H. Pagès, «Plinio en Borges», Stylos, V, 1996, pág. 164. 
Unos versos más adelante el poeta cordobés ilustró todavía la pertinacia mortífera del veneno del basilisco con la patética escena en la que el soldado Murro sufre las consecuencias de haber intentado matar a un basilisco con su lanza:

Quid prodest miseri basiliscus cuspide Murri
transactus? Velox currit per tela uenenum
inuaditque manum; quam protinus ille retecto
ense ferit totoque semel demittit ab armo,
exemplarque sui spectans miserabile leti
stat tutus pereunte manu. [...]

[vv. 828-833]

['¿De qué sirve al pobre Murro haber traspasado al basilisco con la lanza? Veloz corre el veneno por el arma e invade la mano, a la que aquél de inmediato hiere con la espada desenvainada y separa del brazo de un solo tajo; y contemplando el desdichado modelo de su propia muerte, a salvo permanece de pie en tanto su mano muere...'] $]^{7}$.

El curso de los siglos no hizo sino enriquecer la leyenda del basilisco ampliando sus cualidades destructivas. San Isidoro de Sevilla en el capítulo «De las serpientes» de sus Etimologías revisa una a una las criaturas ya descriptas por Lucano; y si la salamandra es eficaz contra los incendios, si una variedad voladora del yáculo posee un veneno tan pernicioso que la víctima sufre la muerte antes que el dolor, si el dragón se enrosca en las piernas del elefante y lo ahoga en los ríos y si la salpuga es una serpiente que no se ve ¿por qué habría de sorprendernos que el basilisco o régulo (también llamado sibilus porque con su silbido mata antes de envenenar), en cuya presencia no hay ave capaz de seguir volando ilesa, pueda exterminar al hombre con la simple fuerza de su mirada? Gracias a San Isidoro sabemos además que al igual que los escorpiones los basiliscos habitan lugares áridos pero se hacen acuáticos cuando llegan a los ríos. Y siguiendo a Plinio - cuya consoladora advertencia ya citada es reiterada en clave cristiana por el obispo de Sevilla («nada dejó el Padre de todas las cosas sin remedio»)- volvemos a enterarnos de que el basilisco muere víctima de la comadreja ${ }^{8}$.

La presencia del basilisco en los textos de los autores que hemos mencionado denuncia la aceptación y difusión del mito ${ }^{9}$. Como ya lo sugiriera

\footnotetext{
${ }^{7}$ Ibid, pág. 168. La traducción es nuestra.

${ }^{8}$ Cf. San Isidoro de Sevilla, Etimologías, Madrid, Biblioteca de Autores Cristianos, 1941, lib. XII, §6-39.

${ }^{9}$ Cf. Stith Thompson, Motif-Index of Folk Literature, Copenhagen, Rosenkilde and Bagger, 1955, vol. I, pág. 355 , s. «Bestias míticas e híbridas», §B12.
} 
Borges, su afirmación en el imaginario del medioevo europeo acaso deba vincularse con el ingreso de su nombre en la Vulgata ${ }^{10}$. La versión de San Jerónimo, buen conocedor de Lucano, recurrió a la voz basiliscus ${ }^{11}$ para traducir el hebreo פפ פח pethén ('serpiente venenosa', 'cobra'), y a su castizo sinónimo régulo para verter las voces ' צפעב tsif'óni y אפעה ef éh, de significados difícilmente diferenciables aunque concordes en su alusión a reptiles venenosos, no necesariamente fantásticos ${ }^{13}$. Siglos más tarde la versión bíblica castellana de Casiodoro de la Reina (1569), revisada a comienzos del siglo XVII por Cipriano de Valera, generalizaría el uso de basilisco en los lugares en los que la Vulgata había empleado régulo ${ }^{14}$. La traducción judeoespañola impresa en Ferrara (1553), de forzada literalidad al texto hebreo original, limitaría basilisco a las formas צ' צsef $^{c} a ́$ y ' צפע tsif óni, que la lexicografía hebrea procuró identificar sin unanimidad con algunas variedades de ofidios existentes ${ }^{15}$. La revisada versión bíblica moderna conocida como Biblia de Jerusalén sustituyó cuidadosamente el basilisco por la víbora o la sierpe venenosa ${ }^{16}$, aunque quizás por falta de referentes contextualmente creíbles prefirió respetar, en cambio, menciones no menos fantásticas como la del חנד tannín «dragón» ${ }^{17}$ o la del שדף מצופף saráf $m e^{c}$ ôféf «dragón volador» ${ }^{18}$.

A lo largo de la Edad Media y del Renacimiento el conocimiento del origen y morfología del basilisco se perfeccionó. En las descripciones del medioevo se suponía al monstruo nacido de un huevo sin yema puesto por un gallo e incubado por un sapo sobre el estiércol. Una variante menos di-

10 Op. cit., pág. 37.

11 Ps. 90, 13, en Biblia Sacra iuxta Vulgatam Clementinam. Nova editio. Logicis partitionibus aliisque subsidiis ornata a Alberto Colunga, O. P. et Laurentio Turrado, Madrid, Biblioteca de Autores Cristianos, 1977.

12 Proverbia, 23,32; Isaias, 59,5, 14,29; Ieremias, 8,17, ibid.

${ }^{13}$ A Hebrew and English Lexicon of the Old Testament with an Appendix containing the Biblical Aramaic based on the lexicon of William Gesenius as translated by Edward Robinson [...]. Edited by Francis Brown [...] with the cooperation of S. R. Driver [...] and Charles A Briggs, Oxford, Clarendon Press, 1907. V.q. Georg Fohrer (ed.), Diccionario del hebreo y arameo bíblicos, Buenos Aires, La Aurora, 1982; A. Comay y D. Yardén, Completo diccionario hebreo-español, Jerusalén-Tel Aviv, Achiasaf, 1976.

${ }^{14}$ La Santa Biblia. Antiguo y Nuevo Testamento, [s.l.], Sociedades Bíblicas de América Latina, 1960.

${ }^{15}$ Biblia en lengua Española traduzida palabra por palabra de la verdad Hebrayca por muy excelentes letrados vista y enmendada por el officio de la Inquisicion. Con priuillegio del yllustrissimo Señor Duque de Ferrara, [Ferrara], [1553]. Cf. A Hebrew and English Lexicon of the Old Testament, op. cit.; cf. H.B. Tristram, Natural History of the Bible, [s.l.], [s.d.], pág. 275 y G. Fohrer (ed.), Wörterbuch zum Alten Testament, Berlin, 1971.

${ }_{16}$ Biblia de Jerusalén. Edición española dirigida por José Ángel Ubieta, Bilbao, Desclée de Brouwer, 1975.

17 Ps. 10,13.

18 Isaias, 14,29. 
fundida es la propuesta por Bartholomaeus Anglicus en su Liber de proprietatibus rerum: el habitáculo del basilisco sería un huevo de áspid robado por el mismo sapo incubador. Santa Hildegarda de Bingen (siglo XII) precisó que el monstruo nacía de la segunda cría del sapo, una vez muerta la primera, y bajo la influencia de la serpiente del Paraíso. En cualquier caso el resultado de tan accidentadas e irregulares gestaciones, en las representaciones más frecuentes, fue un animal con cabeza y ocho patas de gallo, cola de serpiente trífida en la punta, y en la cabeza una corona y ojos centelleantes ${ }^{19}$. Esta vinculación genésica con el gallo fijó su impronta en la etimología popular denunciada por la forma basilicoc (y su variante invertida coqbasile) del francés antiguo, la que a su vez explica la voz basilicok empleada en el inglés de Chaucer ${ }^{20}$.

${ }^{19}$ Bartholomaeus Anglicus, Liber de proprietatibus rerum. Trad. de Fray Vicente de Burgos, Tolosa, Enrique Meyer, 18 de septiembre de 1494, fol. 314r; ap. Admyte [Archivo Digital de Manuscritos y Textos Españoles], Micronet-Ministerio de Cultura, Biblioteca Nacional, 1992, volumen I. Cf. Enciclopedia Universal Ilustrada Europeo-Americana, Barcelona, Espasa, [s.d.], s.v. basilisco Cf. María Leach (ed.), Funk and Wagnalls Standard Dictionary..., loc. cit. Cf. Hans Biedermann, Diccionario de símbolos, Buenos Aires, Paidós, 1993, pág. 66, s.v.

${ }_{20}$ Walter W. Skeat (ed.), The Complete Works of Geoffrey Chaucer. Edited from numerous manuscripts by [...], Oxford, Clarendon Press, 1940, pág. 626, §76. Cf. Frédéric Godefroy, Dictionnaire de l'ancienne langue française et de tous ses dialectes $d u I X^{e}$ au $X V^{e}$ siècle, $\mathrm{Pa}$ ris, Librairie des Sciences et des Arts, 1937, s.v.; Walther von Wartburg, Französisches Etymologisches Wörterbuch, Bonn, Fritz Klopp, 1928, 1.Band, pág. 271, s.v. basiliscus; Jorge Luis Borges y Margarita Guerrero, op. cit., pág. 36. La hibridación de las figuras del gallo y la serpiente manifestó en la tradición léxica inglesa una muy curiosa evolución que, como se verá, tiene puntos de contacto y de divorcio con la correspondiente románica, y castellana en particular. La voz griega i $\chi v \varepsilon v ́ \mu \hat{\omega} v$, lit. 'rastreador', empleada por Herodoto para aludir a un

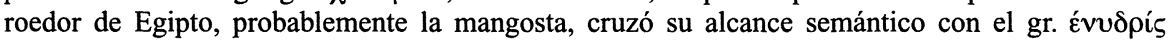
interpretado diversamente como 'nutria' o como un reptil acuático (hydrus 'hidra'); con este último valor $i \chi v \varepsilon v ́ \mu \hat{\omega} v$ fue tomado por Plinio como nombre de un monstruo devorador de los huevos de reptiles, particularmente de los cocodrilos. Brunetto Latini empleó la voz hydrus para designar a un pez que entraba por la garganta del cocodrilo y lo mataba quebrantándole los costados. La voz griega fue traducida en latín tardío por calcatrix o caucatrix ( $\angle$ CALCĀRE, 'pisotear', 'hollar' y más tarde, por extensión, 'seguir las pisadas', 'rastrear'), de donde el francés cocatris. Por tratarse de un reptil acuático y pese a que, como señalamos, fue en su origen animal claramente hostil al cocodrilo, la calcatrix pasó a ser confundida en varias lenguas romances con el cocodrilo mismo (provenzal calcatriz, italiano calcatrice, castellano coquedriz, cacotriz, cocadriz y cocatriz), coincidencia a la que pudo contribuir la semejanza fonética de la forma metatética triunfante cocodrilo (<CROCODILUS, CROCODILLUS) con cocatriz. Cf. Antonio de Nebrija, Dictionarium hispano-latinum, op. cit., s.v. crocodilus; A. Bailly, Dictionnaire grec-français. Éd. revue par L. Séchan et P. Chantraine, París, Ha-

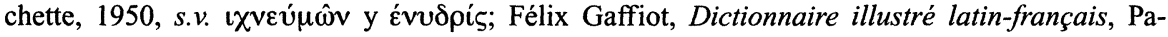
rís, Hachette, 1934, s.v. ichneumōn y hydry̆s; E. Habel (ed.), Mittellateinisches Glossar. 2. Auflage, Paderborn, Ferdinand Schöningh, [s.d.], s.v. calcare; J. Corominas y J. A. Pascual, Diccionario Crítico-Etimológico Castellano e Hispánico, Madrid, Gredos, 1983, s.v. cocodrilo. Llamativo es el hecho de que las traducciones castellana y aragonesa del Libro del tesoro de Brunetto Latini difieren diametralmente en este punto: ambas utilizan las formas hermanas coral y corcorel, respectivamente, para aludir inicialmente al cocodrilo, pero de inmediato la versión castellana emplea como sinónimo la voz cocatriz en tanto la traducción aragonesa 
La sabiduría popular descubrió con alivio que no sólo la comadreja podía enfrentarse al monstruo con éxito; el basilisco también sucumbía al canto mañanero del gallo, razón por la cual los viajeros necesitados de atravesar regiones de basiliscos solían acompañarse del crestado gallináceo macho ${ }^{21}$. Hubo quienes afirmaron que las mujeres estaban exentas de la mortífera capacidad del basilisco, y que incluso podían tomarlos en sus manos sin peligro ${ }^{22}$. Pero el avance más importante en la contienda del hombre con el monstruo lo constituyó el descubrir por una parte que si uno se anticipaba a mirarlo se anulaba su poder maléfico ${ }^{23}$, y por otra que la potencia exterminadora de su mirada podía emplearse en su contra por medio de un espejo que volviese sobre él la capacidad mortífera. El tratado científico conocido como Libro del Tesoro de Brunetto Latini, maestro de Dante, al que ya hemos hecho referencia ${ }^{24}$, narra cómo Alejandro, preocupado por un desfavorable encuentro con basiliscos que diezmaban a sus tropas mirándolas, hubo de hacer construir grandes redomas de vidrio en las que hizo guarecer a sus hombres, de suerte que pudieran ver a los monstruos sin ser vistos y lograr así su exterminio (desde Plinio el transcurso del tiempo había generado una hipérbole más acorde con la peligro-

\footnotetext{
identifica la calçatrix con la ydra; cf. Spurgeon Baldwin (ed.), Brunetto Latini. Libro del tesoro. Versión castellana de Li Livres dou Tresor. Edición y estudio de [...], Madison, The Hispanic Seminary of Medieval Studies, 1989, cap. 131, págs. 69-70; Dawn E. Prince (ed.), The Aragonese Version of Brunetto Latini's Libro del trasoro. Edited by [...], Madison, The Hispanic Seminary of Medieval Studies, 1995, cap. 131, pág. 54. El castellano conservó la identificación de la cocatriz con el cocodrilo y aun con los lagartos o caimanes americanos, como lo atestiguara Pedro Mártir de Anglería para disconformidad y enojo de Gonzalo Fernández de Oviedo, cuya prolijidad descriptiva lo obligó a precisar que «la cocatriz no tiene espiradero alguno mas de la boca $e$ aquestos lagartos o dragones sí, $e$ así menea la superior también como la inferior, y aquestos lagartos que digo no tienen mas de la mandibula baxa", ap. Gonzalo Fernández de Oviedo, Sumario de la natural y general historia de las Indias [ed. facsimilar], Madrid, Espasa-Calpe, 1978, cap. 67, fol. xxxii $r$ y $v$; cf. Alberto M. Salas, $P a-$ ra un bestiario de Indias, Buenos Aires, Losada, 1968, págs. 123-124. En inglés la confusión tomó un rumbo diferente, sobre todo a partir de la traducción de las voces basiliscus y regulus de la Vulgata ya citadas, que en la versión del heresiarca Juan Wycliffe se unificaron en cockatrice, muy probablemente como resultado de una asociación con la cresta, atributo común del monstruo y del gallo (ing. $c o c, c o q$ ), y con la diminuta cría que surge de los huevos de cocodrilo enterrados en la arena junto a los ríos. En este idioma la sinonimia entre basilisk y cockatrice se conserva hasta hoy. Cf. C. F. Onions (ed.), The Oxford Dictionary of English Etymology, Oxford, Clarendon Press, 1966, s.v. cockatrice; J. A. Simpson y E. S. C. Weiner, The Oxford English Dictionary. Second Edition. Prepared by [...], Oxford, Clarendon, 1989, vol. III, s.v. cockatrice.

${ }^{21}$ Cf. The New Enciclopaedia Britannica. 15th. Edition, Chicago, Enciclopaedia Britannica, 1977, II, pág. 1028, s.v. cockatrice.

${ }_{22}$ Pierre Larousse, Grand Dictionnaire Universel, París, 1865, II, pág. 308.

23 Diego de Valera, Crónica de España, Sevilla, Alfonso del Puerto para Michael Dachauer \& García del Castillo, 1482, fol. $6 r$.

${ }^{24}$ V.s. n. 20.
} 
sidad atribuida: en el saber de Brunetto los basiliscos ya medían más de seis pies $^{25}$ ). Una variante técnica de la historia es la referida por la Gesta Romanorum, también del siglo XIII, según la cual, enfrentado Alejandro a la misma o similar emergencia, y siguiendo el consejo de los filósofos en quienes había buscado asesoramiento, dispuso colocar un gran espejo entre la tropa amenazada y el muro desde el cual los basiliscos ejercían su mortal faena; las miradas reflejadas terminaron con los ofensores ${ }^{26}$. Una añeja tradición localmente respetada atribuye la lejana fundación de la ciudad de Basilea a la victoria sobre un basilisco ${ }^{27}$.

$\mathrm{Si}$ bien la primera documentación léxica castellana es, de atenernos a lo señalado por Germán Colón, la de Alfonso el $\mathrm{Sabio}^{28}$, el hecho de que la voz basilisco esté incluida en el Universal Vocabulario de Alfonso de Palencia y en el diccionario hispano-latino de Nebrija, ambos publicados en la última década del siglo $\mathrm{Xv}^{29}$, es indicio de su vitalidad. Un rastreo minucioso en los autores del período excedería el marco que nos hemos fijado, aunque decir que la emplearon Lope de Vega, Góngora, Quevedo y Cervantes significa que la empleó la literatura del Siglo de Oro y del barroco ${ }^{30}$. Los libros de caballerías incorporaron al basilisco de manera plural: como simple figura ornamental en las armas del por ello llamado Caballero de los Basiliscos (Belianis de Grecia) ${ }^{31}$, como integrante de una indiscriminada zoología atemorizadora de los mortales, en compañía de «los ferocíssimos tigres,

25 Spurgeon Baldwin (ed.), Brunetto Latini, Libro del tesoro, op. cit., pág. 73.

${ }^{26}$ Hermann Oesterley (ed.), Gesta romanorum, Berlin, Weidmannsche Buchhandlung, 1872, §139, págs. 493-494.

27 Germán Colón, «Español basilea "horca"», ZRPh, 76, 1960, Heft 5/6, pág. 504.

${ }^{28}$ Germán Colón, ibid., pág. 500. Cf. A. G. Solalinde, Lloyd A. Kasten y Víctor R. B. Oelschläger (eds.), Alfonso el Sabio. General Estoria. Segunda Parte, Madrid, 1957, I, pág. 277b. El registro proporcionado por Colón es anterior en medio siglo a la aparición del vocablo en la obra de Don Juan Manuel, que había citado J. Corominas en el Diccionario Crítico-Etimológico de la Lengua Castellana (1. a ed. Berna, Francke, 1954), si bien la reedición ampliada ya recoge el dato; cf. J. Corominas y J. A. Pascual, Diccionario Crítico-Etimológico Castellano e Hispánico, op. cit., s.v. basilisco.

29 Alfonso de Palencia, Universal vocabulario en latin y romance, ap. Admyte, cit.; Antonio de Nebrija, Dictionarium hispano-latinum. Salamanca, Impresor de la Gramática de Nebrija, 1495. Cf. Samuel Gili Gaya, Tesoro Lexicográfico (1492-1726), Madrid, CSIC, 1947 , I, s.v

${ }^{30}$ Sería tarea ardua relevar la aparición del vocablo en cada uno de los autores del período; como muestra, cf. Carlos Fernández Gómez, Vocabulario de las obras completas de Francisco de Quevedo [s.l.] [s.d.], pág. 259; del mismo autor, Vocabulario completo de Lope de Vega, Madrid, RAE, 1971, I, pág. 337. V.q. Germán Colón, «Español basilea "horca"», art. cit., págs. 502-503.

${ }_{31}$ Lilia E. F. de Orduna (ed.), Jerónimo Fernández. Hystoria del magnánimo, valiente $e$ inuencible cauallero don Belianís de Grecia. Texto crítico, introducción y notas de [...]. I, Kassel, Ed. Reichenberger, 1997, vol. I, pág. 247. Debo a Lilia Ferrario de Orduna los registros de esta voz en los libros de caballerías. 
los crueles leones, los elephantes, los griphos, los dragones [...]» $\rangle^{32}$ o como la bestia que, descrita bajo la novedosa anatomía que a continuación reproducimos, habría de sucumbir bajo la espada de Palmerín de Olivia:

«una cosa muy desmejada que parescía en la fechura cabrón, mas era tan maño como un cavallo e traýa en la fruente dos cuernos muy agudos e derechos y en medio d'ellos traýa una piedra de que salía aquella claridad a manera de olicornio, mas no lo era; e llámase aquel mostruo en aquella tierra basilisco, e era tan bravo e esquivo que más no lo podía ser: tenía los dientes e uñas muy agudas, e ansí como llegó a la compaña de la Ynfanta tomó un hombre entre sus uñas e fízolo pedaços muy presto» ${ }^{33}$.

Al basilisco dedicó Quevedo un romance, ocho de cuyos versos suman a la bíblica la tradición de Lucano y de Plinio:

\section{$[\ldots]$}

«Enfermas, con respirar,

toda la región vacía,

y vuelan muertas las aves

que te pasan por encima.»

(vv. 13-16)

\section{$[\ldots]$}

Para pisado eres bueno,

que la Escritura lo afirma, pues sobre ti y sobre el áspid

dice que el justo camina.»

(vv. 61-64) ${ }^{34}$.

Para entonces ya la Crónica de España de Diego de Valera, compuesta también en el último tercio del siglo XV, había confirmado en dos pies el tamaño del basilisco y anunciado la acción basilicida del olor de la ruda verde. El Nobiliario vero de Fernando Mejía, a su vez, había puntualizado

${ }^{32}$ Daniel Eisenberg, Diego Ortúñez de Calahorra. Espejo de príncipes y cavalleros [El Cavallero del Febo]. Edición, introducción y notas de [...], Madrid, Espasa-Calpe, 1975, págs. 39-40.

${ }_{33}$ Giuseppe di Stefano (ed.), El libro del famoso e muy esforçado cavallero Palmerín de Olivia. Testo critico a cura di [...], Pisa, Università di Pisa, 1966 (Studi sul Palmerín de Olivia, I), pág. 449. La tradición según la cual el basilisco llevaba un rubí en medio de su frente figura ya en el texto en francés antiguo Li Hystoire de Julius Ceser de Jehan de Tuim, cf. Erhard Lommatzsch, Altfranzösisches Wörterbuch Adolf Toblers nachgelassene materialen bearbeitet [...] herausgegeben von [...], Berlin, Weidmannsche Buchhandlung, 1925, 1. Band, pág. 858 , s.v. baselique.

34 «El basilisco», ap. José Manuel Blecua (ed.), Francisco de Quevedo. Obras completas. I. Poesía original, Barcelona, Planeta, 1963, págs. 794-795. 
que el efecto de la mirada de la criatura también podía ser anulado por la piedra carbunco ${ }^{35}$.

El basilisco hubo de sobreponerse a otros ataques de consideración, aunque nacidos éstos de la periódica necesidad del hombre de conjurar sus propios fantasmas. En términos de alegoría cristiana el basilisco fue interpretado como símbolo del mal ministro o funcionario ${ }^{36}$; también de la mujer disoluta, destructora de los hombres incautos que sucumben a ella por no haber sabido reconocerla primero ${ }^{37}$. El racionalismo científico, por su parte, procuró documentar su verdadera apariencia; en la segunda mitad del siglo XVI Ulises Aldrovando no sólo declaró en su Ornithologia haber visto un ejemplar muerto (cabeza aguzada, color azafranado, más de tres palmos de largo, motas blancas sobre el vientre y piel celeste) sino postuló la existencia de variedades silvestres y domésticas ${ }^{38}$. A fines del mismo siglo se adjudicó al veneno del basilisco el devastador efecto morbífico de la sífilis $^{39}$. Ya hemos aludido al metódico escamoteo de basiliscos en las traducciones bíblicas recientes. Modernamente se pretendió explicar la reiterada vinculación del basilisco con las cavernas en las que la tradición establecía su madriguera letal: el resuello mortal del basilisco no sería otra cosa que el resultado de la legendaria perplejidad ante un hecho físico, esto es la acción de los gases deletéreos presentes en cuevas y subterráneos que con frecuencia acababan con la vida de poceros y mineros ${ }^{40}$.

En nuestro idioma la previsible capacidad connotativa del vocablo fue aprovechada por la ciencia astronómica para nombrar a la estrella de primera magnitud conocida también como Régulo o Estrella regia. Germán Colón ha postulado que la voz de germanía basilea 'horca' remite, tras desandar una cadena asociativa, al étimo «basilisco»" ${ }^{41}$. Integrando el campo semántico de las armas de fuego, que gustó aludir variadamente a nombres de reptil (áspid, culebrina, dragoncillo), bajo el nombre de basilisco se conoció además una pieza de artillería de bronce muy empleada en el siglo XVI. Y desde entonces ha venido también aludiendo metafóricamente a

\footnotetext{
${ }^{35}$ Diego de Valera, Crónica de España, op. cit.; Fernando Mejía, Nobiliario vero, Sevilla, Pedro Brun \& Juan Gentil, 30 de junio de 1492. Ap. Admyte, cit.

${ }^{36}$ Pierre Berçuire, Ovidius moralizatus. Trad. castellana del siglo XIV, MS. Bibl. Nacional de Madrid n. ${ }^{\circ} 10144$, ap. Admyte, cit.

37 Jean Chevalier y Alain Gheerbrant, Dictionnaire des symboles. Mythes, rêves, coutumes, gestes, formes, figures, couleurs, nombres, París, Seghers, 1973, pág. 179.

${ }^{38} \mathrm{Cf}$. Alejandro Guichot y Sierra, El basilisco. Datos y materiales recogidos y ordenados para el estudio del mito por [...], Sevilla, Alejandro Guichot, 1884 (Biblioteca de las tradiciones populares españolas, III), pág. 53.

${ }^{39}$ Hans Biedermann, Diccionario..., op. cit.

${ }^{40}$ Cf. Enciclopedia Universal Ilustrada Europeo-Americana, Barcelona, Espasa-Calpe, [s.d.], s.v.

${ }^{41}$ Art. cit., pág. 500
} 
la persona furiosa o dañina ${ }^{42}$, valor semántico que hace pocos años saltó a la curiosidad pública argentina cuando un afamado político se sirvió de él para aludir a un controvertido ministro de temperamento bravío ${ }^{43}$.

La referencia nebrisense al basilisco, apenas cumplido el descubrimiento de América, es aviso de su desplazamiento transoceánico. Que su figura hubo de poblar el mundo fantástico del conquistador, portador de la imaginería medieval, lo podemos inducir analógicamente de la recurrencia de sirenas, grifos y unicornios que habitaron las crónicas americanas así como de la evidencia de la nutrida literatura de caballerías introducida en el continente nuevo: el Caballero del Febo, el Belianis de Grecia y el Palmerín de Olivia, para ceñirnos a las obras ya citadas, integraron las muchas preferencias literarias profanas de los viajeros a América, legos y clérigos, que con inútil frecuencia las delegaciones inquisitoriales denunciaban y las audiencias virreinales prohibían ${ }^{44}$. La casualidad de un documento de Cartagena de Indias de 1534, que habla de «demonios o basiliscos», viene a avalar austeramente lo que llevamos dicho ${ }^{45}$.

Quizás no sea descaminado postular que los nutridos contingentes iniciales de inmigrantes andaluces pudieron ser vehículo privilegiado de la leyenda hacia América, como con certeza lo fueron de otros rasgos culturales y lingüísticos. En el mediodía peninsular todavía hacia fines del siglo pasado las madres solían reprender a un hijo revoltoso con la expresión «iEstate quieto, basilisco, demonio coronado!», y se dejaba oír alguna copla alusiva como «Si yo fuera basilisco / con la vista te matara, / y te sacara del mundo / porque nadie te gozara» ${ }^{46}$.

\footnotetext{
${ }^{42}$ Enciclopedia Universal Ilustrada Europeo-Americana, op. cit. Cf. DRAE [Diccionario de la lengua española, Madrid, Real Academia Española. 21. ${ }^{a}$ ed., 1992], s.v. También en dialecto cremonés el adjetivo bazelesk califica a la persona irascible, iracunda o furiosa, cf. W. Meyer-Lübke, Romanisches Etymologisches Wörterbuch, Heidelberg, Carl Winters Universitätsbuchhandlung, 1935, pág. 82, s.v. basiliscus.

${ }^{43}$ Fue Raúl Alfonsín quien el 20 de enero de 1995 en áspera respuesta a una previa descalificación hecha pública por el entonces ministro de Economía Domingo Cavallo tildó a éste de «autoritario, energúmeno y basilisco». Lo desusado del término en el dominio rioplatense actual se evidenció en el hecho de que varios diarios de la capital argentina se vieron obligados a rastrear en el Diccionario de la Real Academia el sentido del vocablo, cf. La Nación, 21 de enero de 1995, pág. 1 (donde la definición de la palabra se destaca en un recuadro central), y Página 12, 21 de enero de 1995, pág. 7. Un análisis de la polisemia del vocablo en el marco del discurso que incluyó los agresivos epítetos del ex presidente intentó en esos días Carlos Sapéne, «Alfonsín contra el basilisco», Página 12, 9 de febrero de 1995, pág. 6.

${ }^{44}$ Cf. Alberto M. Salas, Para un bestiario de Indias, op. cit., v.s. n. 19. V. sobre el particular la abundantísima información que provee Irving A. Leonard, Los libros del Conquistador, México, Fondo de Cultura Económica, 1953, págs. 101, 143 y passim.

${ }^{45}$ Peter Boyd-Bowman, Léxico hispanoamericano del siglo XVI, Madison, The Hispanic Seminary of Medieval Studies, 1987 [Ed. en microfichas, que amplía considerablemente el contenido de la más difundida de Londres, Támesis, 1971], s.v.

${ }^{46}$ Alejandro Guichot y Sierra, op. cit., pág. 14.
} 
Si bien la exuberancia de la fauna del Nuevo Continente concedió a la voluntad positivista de los naturalistas la anuencia para identificar al basilisco con un inofensivo iguánido de las regiones cálidas de México y de América del Sur, citado hoy por el diccionario de la Real Academia y rebajado a distribuirse taxonómicamente entre el basiliscus americanus y el mitratus $^{47}$, el monstruo original permaneció, en cambio, en la memoria popular con sus devastadoras potencias intactas. En su forma menos conciliadora nuestro folclore retuvo la existencia del basilisco en la creencia de que el monstruo nace de un huevo fecundado por un gallo viejo, o más concretamente por uno de siete años ${ }^{48}$ o en el último año de su vida ${ }^{49}$. En la campaña de la provincia de Catamarca se sabía, y acaso aún se sepa, que si un huevo no se incuba dentro de las veinticuatro horas posteriores a su postura da inexorable nacimiento a un basilisco - pequeño lagarto de un ojo único según algunos, escuerzo de color parduzco y ojos grandes y luminosos según otros - por lo que se aconseja que todo huevo pequeño sea preventivamente arrojado al fuego o bien a un corral de cabras, animal al que se atribuye una vista más poderosa que la del monstruo ${ }^{50}$. Hay en esa provincia quien sostiene que el basilisco segrega un líquido de mortales efectos, y quien ha comparado su pequeña y horrible figura con la de un pequeño payaso por haberlo visto bailotear con algo así como un bonete y zapatos parados ${ }^{51}$. En la provincia de Buenos Aires se optaba por enterrarlo en un hoyo profundo y aplanar la tierra de la superficie, después de lo cual se acostumbraba trazar una cruz con un cuchillo o un palito; una colega nativa nos recordaba que en las zonas rurales de Salta se recomenda-

${ }^{47}$ Cf. DRAE, s.v.; Enciclopedia Universal Ilustrada Europeo-Americana, op. cit.; cf. Der Grosse Brockhaus, Wiesbaden, Brockhaus, 1953, s.v.

${ }^{48}$ Félix Coluccio, Diccionario de creencias y supersticiones. 3ra. ed., Buenos Aires, Corregidor-Ediciones Culturales Argentinas, 1990, pág. 51.

${ }^{49}$ Orestes di Lullo, El folklore de Santiago del Estero (Material para su estudio y ensayo de interpretación), Tucumán, Universidad Nacional de Tucumán, 1943, págs. 189-190.

${ }^{50}$ Carlos Villafuerte, Voces y costumbres de Catamarca, Buenos Aires, Academia Argentina de Letras, 1961, I. s.v.; cf. Orestes di Lullo, op. cit. En oportunidad de leer la comunicación a que aludimos en la nota inicial del presente artículo, un grupo de alumnos de la Universidad Nacional de Catamarca nos dio a conocer un trabajo que desconocíamos titulado «El basilisco», fragmento textual de Allpamisqui de Rafael Cano (1938) y reproducido por extraña casualidad en el suplemento cultural de un periódico local dos días antes de nuestra exposición; creemos haber ampliado considerablemente la información allí contenida; cf. $L a$ Unión, 15 de septiembre de 1996. La incineración como remedio definitivo contra el basilisco tiene un curioso antecedente histórico: la tradición local registra que en 1474 en la ciudad de Basilea un gallo de once años puso un huevo, acontecimiento que llevó al alarmado consejo de la ciudad a tomar la determinación de hacerlo decapitar y quemar junto con su ominosa postura, cf. Germán Colón, «Español basilea "horca"», art. cit., pág. 505.

51 Berta Elena Vidal de Battini, Cuentos y leyendas populares de la Argentina, Buenos Aires, Ediciones Culturales Argentinas, 1984, vol. VIII, págs. 456-457. 
ba arrojar ceniza sobre la apresurada sepultura del engendro. Estas precauciones no son excesivas porque si la demora o la inadvertencia permiten el nacimiento del basilisco es de temer que éste corra a ocultarse en las paredes de las casas, desde donde comenzará a ejercer su maléfico oficio, de preferencia sobre las mujeres; esta situación, empero, no es irreversible, porque si el daño es certera y oportunamente diagnosticado el recurso más efectivo será que la víctima se siente de espaldas al nido, al que deberá mirar durante dos horas diarias a través de un espejo hasta que la fuerza ejercida por la mirada del régulo sea efectivamente contrarrestada ${ }^{52}$. Una caricaturesca prolongación del recurso empleado por Alejandro, referido ya en líneas previas ${ }^{53}$, es la del ingenioso paisano de San Luis que, enterado de la existencia de un basilisco apostado en un camino y ante cuya mirada sucumbía cuanto cristiano a animal acertaba a pasar por allí, logró eliminarlo atravesándole un burro con un espejo en la frente ${ }^{54}$.

En algunas regiones de Chile el basilisco es una serpiente alada o un gallo-reptil de cresta roja nacido de un huevo que si no fue puesto por un gallo lo fue por una gallina de más de cuatro años que cantó como un gallo; allí es cosa sabida que si un mal azar permite su supervivencia el basilisco saldrá por las noches para succionar la sangre de las personas mientras duermen; y si por acaso su mirada recayese en un brazo o pierna, la víctima conservaría la vida pero con esos miembros definitivamente paralizados $^{55}$. Sin alusión al basilisco mismo, una extensión velada del mito parece sobrevivir en algunas regiones del Llano venezolano, donde se advierte que el primer huevo puesto por una gallina no debe comerse pues carece de yema, en lugar de la cual trae un tuqueque 'lagartija', así como también es peligroso el último de una serie, que suele portar un pequeño $m a$ to 'lagarto' de peligrosa mordedura ${ }^{56}$.

Inútil parece haber sido la postulación de que el engendro surgido del huevo pudo haber sido el producto legítimo de una lagartija verde que su-

\footnotetext{
${ }^{52}$ Así lo precisa un relato enviado por una maestra de la escuela de Fuentes (provincia de Santa $\mathrm{Fe}$ ) en su respuesta a la Encuesta folclórica del Magisterio realizada por el Ministerio Nacional de Educación argentino en 1921; v. el texto manuscrito archivado en el Instituto Nacional de Antropología y Pensamiento Latinoamericano (Buenos Aires), vol. SF, N. ${ }^{\circ} 69$. Cf. Tito Saubidet, Vocabulario y refranero criollo, Buenos Aires, Kraft, 1962. 6ta. ed., pág. 35 .

${ }^{53}$ V.s. n. 26.

${ }^{54}$ B. E. Vidal de Battini, op. cit., pág. 460. Cf. José Ignacio Maldonado, art. cit., pág. 49. Para una más cómica derivación de este relato, vi. n. 58.

55 Julio Vicuña Cifuentes, Mitos y supersticiones. Estudios del folklore chileno recogidos de la tradición oral, Santiago, Nascimento, 1947, 3. ${ }^{a}$ ed., págs. 13-14.

${ }^{56}$ Miguel Acosta Saignes, Estudios de folklore venezolano. Serie de Folklore. Caracas, Instituto de Antropología e Historia, Facultad de Humanidades y Educación, Universidad Central de Venezuela, 1962, pág. 165.
} 
po aprovechar la involuntaria hospitalidad de un nidal de gallinas para hacer empollar su propia postura ${ }^{57}$. Por la difusión diatópica del vocablo sospechamos que en amplias regiones rurales de nuestro territorio sobrevive aún la convicción más o menos encubierta de que en el interior de un huevo defectuoso, diminuto, huero o sin cáscara puede estar empollándose la horrenda criatura ${ }^{58}$. De esta amenazante expectativa se origina la lexía compuesta huevo basilisco para denotar al 'huevo pequeño puesto por una gallina vieja' que en el curso de una encuesta lingüística realizada en Santiago del Estero (Argentina) obtuvimos en 1994 en la localidad de Brea Pozo, o la del 'huevo puesto sin cáscara' que nos fue suministrada por los informantes de la capital santiagueña y de Campo Gallo ${ }^{59}$. También como regionalismo referido al huevo atrofiado sin yema lo recogió en Salta José Vicente Solá ${ }^{60}$. En procura de confirmar el alcance del vocablo inquirimos en la ciudad de Buenos Aires a una señora de setenta años, porteña de segunda generación, familiarizada en su niñez con los gallineros que solían alborotar los fondos de las casas de barrio, por el nombre del huevo que no

\footnotetext{
57 José Ignacio Maldonado, «El basilisco», Primeras Jornadas de Investigación Folklórica Sanluiseña, Centro de Investigaciones Folklóricas «Dr. Dalmiro S. Adaro», San Luis, 1963, pág. 49.

${ }^{58}$ Cf. Pedro Inchauspe, Voces y costumbres del campo argentino. Buenos Aires, Rueda, 1942; Julián Cáceres Freyre, Diccionario de regionalismos de la provincia de La Rioja, Buenos Aires, Instituto Nacional de Investigaciones Folklóricas, 1961. La misma creencia corría en la campaña francesa en el siglo pasado; cf. La Grande Encyclopédie. Inventaire raisonné des sciences, des lettres et des arts, París, Lamirault [s.d.], s.v. B. E. Vidal de Battini recoge ocho relatos de la leyenda en Santiago del Estero, Catamarca, La Rioja y San Luis, op. cit., págs. 453-460. El carácter eminentemente rural de esta creencia así como su considerable alcance diatópico en el territorio argentino pueden inducirse de su inclusión en clave satírica en un cómic de gran popularidad publicado en el diario Clarin (Buenos Aires) y recopilado desde 1976 hasta el presente en veintidós volúmenes. Su autor, Roberto Fontanarrosa, es oriundo de Rosario (provincia de Santa $\mathrm{Fe}$ ). Uno de los episodios iniciales está consagrado a narrar cómo el gaucho Inodoro Pereyra, el protagonista, debe enfrentarse al basilisco, quien retiene en su poder al perro Mendieta, fiel acompañante de Inodoro. En procura de la ayuda de un hipnotizador que podría prestar su ciencia para recuperar al perro secuestrado, y ante la pregunta de aquél, Inodoro define al basilisco en su paródico dialecto gauchesco como «una especie de gusano que sale del último güevo que pone una gayina vieja. Tiene un solo ojo y si te mira te achura». Inodoro, fiel a la tradición ortodoxa, aunque modernizado en su armamento, vencerá finalmente al "animal de mirada definitiva», munido de un espejo frontal de otorrinolaringólogo ceñido a su cabeza. Cf. Fontanarrosa, Las aventuras de Inodoro Pereyra iEl renegau!, vol. 2, Buenos Aires, Ediciones de La Flor, 1976, 10. ${ }^{a}$ ed., [s.p.].

59 Recogimos estas respuestas en oportunidad de realizar ocho encuestas lingüísticas en la provincia de Santiago del Estero como contribución para la elaboración del Atlas Lingüístico de Hispanoamérica, concebido y dirigido por Manuel Alvar. Cf. José Luis Moure, «Notas léxicas sobre el español de Santiago del Estero», Boletín de la Academia Argentina de Letras LXI (1997), N. ${ }^{\circ}$ 239-240, págs. 53-71. La misma lexía registra B. E. Vidal de Battini en un relato oral recogido en Tucumán, op. cit., pág. 453.

${ }^{60}$ José Vicente Solá, Diccionario de regionalismos de Salta (República Argentina), 2. ${ }^{a}$ ed., Buenos Aires, Amorrortu, 1947, pág. 47.
} 
tiene yema; «-Huevo basilico [sic]» fue su respuesta, y completó: «-el basilico es un huevo que ponen las gallinas viejas y que no sirve para nada; lo recuerdo bien porque así me llamaba mi mamá cuando se enojaba». Esta forma basilico parece el explicable resultado de la fijación de una realización con $-s$ implosiva relajada hasta su silenciamiento, acaso afectada además por analogía con basílico, 'albahaca' en italiano, que suponemos vocablo frecuente en las comunidades iniciales de ese origen ${ }^{61}$.

«En el curso de las edades», señaló Borges, «el basilisco se modifica hacia la fealdad y el horror y ahora se lo olvida ${ }^{62}$. Sospechamos que nuestro escritor desconoció la proyección americana del viejo mito. Veinte siglos no han bastado para aniquilar al basilisco; en la leyenda, en la superstición, en el folclore o en la supervivencia casual de una expresión dialectal, América sigue dando amparo a esta inconjurable pesadilla de Occidente.

\footnotetext{
${ }^{61}$ En francés moderno la deleción disimilatoria de la segunda sibilante produjo una evolución fonética similar, que llevó a la permanencia de una voz única basilic hacia la que confluyeron ambos étimos. Cf. Ernst Gamillscheg, Etymologisches Wörterbuch der französischen Sprache, op. cit., s.v.

${ }^{62}$ Op. cit., pág. 36.
} 